ARQGA / 896

\title{
TESTE DO H, NO AR EXPIRADO NA AVALIAÇÃO DE ABSORÇÃO DE LACTOSE E SOBRECRESCIMENTO BACTERIANO NO INTESTINO DELGADO DE ESCOLARES
}

\author{
Jairo César dos REIS*, Mauro Batista de MORAIS** e Ulysses FAGUNDES-NETO***
}

RESUMO - Estudos realizados há mais de 10 anos demonstraram que a deficiência ontogenética de lactase é freqüente na população brasileira. Entretanto, esses estudos se basearam no incremento da glicemia após sobrecarga de doses não utilizadas habitualmente na dieta. Atualmente, aceita-se que a avaliação da absorção da lactose com o teste do hidrogênio no ar expirado é mais apropriada que o teste da curva glicêmica. Por outro lado, a enteropatia ambiental sintomática elou assintomática constituem um grave problema de saúde pública em grupos populacionais de baixo nível sócioeconômico de nosso meio. A ocorrência de sobrecrescimento bacteriano no intestino delgado de crianças com enteropatia ambiental, foi caracterizada em crianças moradoras em favelas. Sobrecrescimento bacteriano no intestino delgado é caracterizado pela presença de bactérias pertencentes à flora colonica no intestino delgado. Objetivando avaliar a freqüencia de má absorção de lactose e determinar a ocorrência de sobrecrescimento bacteriano no intestino delgado em crianças escolares, através do teste do $H_{2}$ no ar expirado, investigaram-se 83 alunos de uma escola localizada na região periférica da cidade de Marília, Estado de São Paulo, após sobrecarga oral de lactose e lactulose. Foram colhidas também amostras de fezes para pesquisa de parasitas. Má absorção de lactose foi observada em 19 (22,9\%) escolares e intolerância à lactose em 10 (12,0\%). Sobrecrescimento bacteriano no intestino delgado foi identificado pelo teste do $\mathrm{H}_{2}$ no ar expirado em $6(7,2 \%)$ dos 83 escolares. Giardia lamblia foi o parasita mais freqüentemente isolado nas fezes dos escolares. A ocorrência de deficiência ontogenética de lactase observada neste grupo de crianças foi semelhante ao relatado para populações caucasianas. Sobrecrescimento bacteriano foi encontrado neste grupo de crianças assintomáticas, podendo refletir as condições desfavoráveis de seu meio ambiente.

DESCRITORES - Testes respiratórios. Teste de tolerância à lactose. Bactérias, crescimento e desenvolvimento. Intestino delgado. Lactose. Lactulose. Estudantes.

Disciplina de Gastroenterologia Pediátrica da Universidade Federal de São Paulo - Escola Paulista de Medicina - UNIFESP-EPM.

* $\quad$ Mestre em Pediatria pela Disciplina de Gastroenterologia Pediátrica do Departamento de Pediatria da UNIFESP-EPM.

** Professor Associado. Livre Docente e Chefe da Disciplina de Gastroenterologia Pediátrica, do Departamento de Pediatria da UNIFESPEPM.

*** Professor Titular da Disciplina de Gastroenterologia Pediátrica e Chefe do Departamento de Pediatria da UNIFESP-EPM.

Endereço para correspondência: Dr. Ulysses Fagundes Neto - Departamento de Pediatria - Universidade Federal de São Paulo - Rua Botucatu, 598 - 04023-062 - São Paulo, SP. 


\section{INTRODUÇÃO}

O teste do hidrogênio no ar expirado é uma técnica que vem sendo utilizada cada vez mais freqüentemente em clínica e pesquisa, por ser método não invasivo e preciso para a avaliação da absorção de carboidratos e caracterização de sobrecrescimento bacteriano no intestino delgado (SCBID) $)^{(14)}$.

Estudos realizados no passado demonstraram que a deficiência ontogenética de lactase é freqüente na população brasileira ${ }^{(8,28)}$. Entretanto, esses estudos se basearam no incremento da glicemia após sobrecarga de doses não utilizadas habitualmente na dieta. Atualmente, aceita-se que a avaliação da absorção da lactose com o teste do hidrogênio no ar expirado é mais apropriada que o teste da curva glicêmica $^{(26)}$. A deficiência ontogenética de lactase pode se manifestar por má absorção de lactose acompanhada ou não de intolerância, caracterizada por manifestações clínicas como diarréia, dor e distensão abdominal ou flatulência ${ }^{(5)}$.

A enteropatia ambiental sintomática e/ou assintomática constitui grave problema de saúde pública em grupos populacionais de baixo nível sócio-econômico em nosso meio ${ }^{(10)}$. A ocorrência de SCBID foi descrita em crianças moradoras em favelas ${ }^{(10)}$ e se caracteriza pela presença de bactérias pertencentes à flora colônica no intestino delgado ${ }^{(14)}$. Até o presente, são poucos os estudos que utilizaram o teste do hidrogênio no ar expirado para investigar a ocorrência de SCBID em crianças moradoras em condições ambientais não apropriadas.

Assim, este estudo foi planejado com os objetivos de avaliar a freqüência de má absorção e intolerância à lactose e a ocorrência de SCBID.

\section{CASUÍSTICA E MÉTODOS}

O presente trabalho foi desenvolvido na Escola Estadual de Ensino Fundamental
Antonio Garcia Egéa, localizada na periferia da cidade de Marília, interior do Estado de São Paulo, situada em bairro habitado, principalmente, por operários e diaristas que têm empregos temporários na lavoura: os chamados “bóias-frias". Próximo à escola, existe um aglomerado de habitações, que preenche as características propostas por $\mathrm{VIARO}^{(31)}$, para a definição de favela: "conjunto de habitações construídas de modo tosco e desprovidos de recursos higiênicos, geralmente localizadas em morros e nas periferias das cidades e, em algumas delas, nos centros urbanos. Persistem, em todos os locais, a rudeza e a falta de higiene, crescendo a importância no que diz respeito às suas conseqüências sociais e sanitárias". Por se localizar nos limites da cidade, a escola tem, também, alunos oriundos de chácaras, sítios e fazendas.

\section{CASUÍSTICA}

Todos os 83 alunos regularmente matriculados na escola foram incluídos no trabalho. Quando da organização dos grupos para a realização das provas com o hidrogênio, se observada a presença de diarréia, vômitos e/ou o uso de antibióticos por via oral por qualquer motivo, 30 dias eram aguardados para a realização do teste.

\section{MÉTODOS}

\section{Inquérito pessoal, alimentar e habita- cional}

Por meio de entrevista com as mães, foram obtidas as seguintes informações: antecedente pessoal de internação, hábito de ingestão de leite (em copos de $240 \mathrm{~mL} / \mathrm{dia}$ ), condições de saneamento básico (água encanada, de poço ou de mina, rede de esgoto, fossa séptica ou esgoto a céu aberto) e as condições de habitação (alvenaria, madeira ou barraco). Foi considerado barraco "habitação construída com pedaços de madeira, papelão e latas, que comumente apresenta frestas nas paredes e telhas, além de, muitas vezes, ter o chão de terra, sem qualquer tipo de revestimento"(31).

\section{Avaliação do estado nutricional}

Todos os alunos foram pesados e medidos. Em seguida, foram aplicados os critérios de WATERLOW ${ }^{(32)}$ para avaliação do estado nutricional.

\section{Prova do $\mathrm{H}_{2}$ no ar expirado após sobre- carga oral com lactose}

Após jejum de 8 horas, foi coletado o ar expirado basal, que correspondeu à amostra de jejum.

A coleta foi realizada com dispositivo "no rebreathing valve set up", da Quintron Instrument Co. Inc., Menomonee Falls, Wisconsin, EUA, que consiste em um intermediário contendo uma válvula interna que permite a passagem do ar em uma única via, sem retorno. Na extremidade de entrada, um bocal adaptado ao intermediário é perfeitamente acoplado à boca do aluno, enquanto que o outro extremo do intermediário contém um saco de $250 \mathrm{~mL}$, hermeticamente fechado, possuindo apenas um local para retirada do ar. Após este saco estar repleto, $50 \mathrm{~mL}$ de ar foram retirados por uma seringa de polietileno, que é adaptada a uma torneira localizada na sua extremidade distal.

A seguir, aos escolares foram oferecidos $18 \mathrm{~g}$ de lactose (Certificado de Análise Galena Química e Farmacêutica), em solução aquosa a $10 \%$.

Após a ingestão da lactose, foram colhidas amostras de ar expirado aos 15, 30, 45, 60, 90 e 120 minutos. 
As amostras de ar eram imediatamente analisadas em um cromatógrafo de gás Quintron Microlyser modelo 12i (Quintron Instrument Co. Inc., Menomonee Falls, Wisconsin, EUA).

Foram considerados maus absorvedores de lactose, os indivíduos que apresentassem incrementos de $\mathrm{H}_{2}$ acima de 20 partes por milhão (ppm), em relação ao jejum $\left(\mathrm{DH}_{2}\right)$, em qualquer amostra coletada, após a ingestão de lactose ${ }^{(17)}$.

Para análise comparativa, aqueles que tiveram valores de $\mathrm{DH}_{2}$ acima de $10 \mathrm{ppm}$, em relação aos valores de jejum, também foram selecionados.

Os estudantes foram reavaliados 24 horas após a realização do exame para determinar a ocorrência de possíveis sinais e/ou sintomas de intolerância à lactose. Foram considerados intolerantes à lactose os estudantes que tivessem apresentado os seguintes sinais e/ou sintomas durante este intervalo de tempo: dor abdominal, distensão abdominal, flatulência e/ou diarréia.

\section{Prova do $\mathrm{H}_{2}$ no ar expirado após sobre- carga oral com lactulose}

Um tempo mínimo de 72 horas de intervalo foi obedecido entre as provas.

Em seguida, $10 \mathrm{~g}$ de lactulose (país de origem: Alemanha, Certificado de Análise: Galena Química e Farmacêutica Ltda.) a 50\% foi administrada por via oral. Este substrato foi diluído em água a 10\%. Após ingestão, foram coletadas amostras de ar expirado nos seguintes tempos: $15,30,45,60,90$ e 120 minutos.

A mesma metodologia de coleta do ar expirado utilizada para a lactose, foi empregada com a lactulose.

Em condições normais, a lactulose é fermentada no cólon, ocorrendo liberação de hidrogênio somente após 60 minutos da ingestão da mesma ${ }^{(6,20)}$.

O teste foi interpretado da seguinte maneira:

a) Teste positivo: quando foi encontrado pico de $\mathrm{H}_{2}$ superior a $20 \mathrm{ppm}$, em relação ao jejum, até 60 minutos após a ingestão da lactulose;

b) Teste negativo: valor de $\mathrm{H}_{2}$ no ar expirado igual ou inferior a $20 \mathrm{ppm}$, em relação ao jejum, até 60 minutos após a ingestão da lactulose.

\section{Protoparasitológico}

Exame parasitológico de fezes foi realizado em todos os alunos pelos métodos de Faust, Hoffman e Rugai ${ }^{(12)}$.

\section{Método Estatístico}

Foi utilizado o teste exato de Fisher ${ }^{(25)}$ para tabelas $2 \times 2$, derivadas de tabelas $2 \times 4$, devido às restrições de Cochran ${ }^{(25)}$, com a finalidade de estudar a associação entre as variáveis tolerância à lactose, má absorção de lactose e ocorrência de proliferação bacteriana no intestino delgado, para o qual fixou-se em 0,05 ou $5 \%(\mathrm{P}<0,05)$ o nível de rejeição da hipótese de nulidade.

\section{RESULTADOS}

Dos 83 alunos estudados, 45 (54,2\%) eram meninos. A idade variou de 7 a 15 anos, com mediana de 10 anos.

Cinqüenta e sete $(68,6 \%)$ ingeriam, pelo menos, um copo de leite por dia, sendo a média de 2,1 copos/dia. Vinte e seis $(31,4 \%)$ deles não tomavam leite.
Setenta e cinco $(90,4 \%)$ escolares encontravam-se eutróficos, enquanto que oito $(9,6 \%)$ deles apresentavam algum grau de desnutrição, a saber: desnutrição aguda (cinco), desnutrição pregressa (dois) e desnutrição crônica (um).

Do total de alunos, 54 (65\%) moravam no perímetro urbano e 20 (24\%) destes eram habitantes da favela, enquanto que $29(34,9 \%)$ viviam na zona rural. Sessenta e cinco $(78,3 \%)$ moravam em casa de alvenaria e $18(21,7 \%)$ moravam em casa de madeira. As casas de 61 $(73,5 \%)$ alunos eram abastecidas por água encanada, $15(18,0 \%)$ por água de poço e 7 $(8,4 \%)$ por água de mina.

Em relação à drenagem de esgoto das residências dos alunos, 41 (49,4\%) deles tinham suas casas ligadas à rede de esgoto $\mathrm{e}$ $37(44,6 \%)$ à fossa séptica. Esgoto a céu aberto foi constatado em $5(6,0 \%)$ habitações dos alunos estudados.

\section{Teste do $\mathrm{H}_{2}$ no ar expirado com lactose}

Com ponto de corte de $\mathrm{DH}_{2}>20 \mathrm{ppm}$, $19(22,9 \%)$ alunos foram classificados como maus absorvedores de lactose, e com $\mathrm{DH}_{2}>10$ ppm, $37(44,6 \%)$ alunos.

\section{Tolerância à lactose}

Intolerância à lactose ocorreu em 10 (12,0\%) alunos. Os sintomas de intolerância observados foram: diarréia (quatro); distensão abdominal (três); flatulência (um) e diarréia, dor abdominal, distensão abdominal (dois).

\section{Teste do $\mathrm{H}_{2}$ no ar expirado com lactulose}

Em seis $(7,2 \%)$ escolares, o teste do $\mathrm{H}_{2}$ no ar expirado revelou-se positivo para sobrecrescimento bacteriano, ou seja, um 
incremento de 20 ppm de $\mathrm{H}_{2}$ em relação ao jejum, durante os primeiros 60 minutos de exame.

\section{Protoparasitológico}

Do total dos exames protoparasitológicos realizados, $30(36,1 \%)$ apresentaram-se positivos para algum tipo de parasita. Em nove deles, dois parasitas foram encontrados, e em dois observaram-se três parasitas. Giardia lamblia foi o parasita mais freqüente, identificado em $18(21,6 \%)$ exames, seguido por Ascaris lumbricoides em 7 (8,4\%).

\section{Absorção e tolerância à lactose Com $\Delta H_{2}>20$ ppm}

Sinais de intolerância, mas sem alteração da prova do $\mathrm{H}_{2}$, foram observados em quatro alunos. Dezenove alunos foram classificados como maus absorvedores.

O teste exato de Fisher mostrou associação estatisticamente significante $(\mathrm{P}<0,01)$, entre absorção e tolerância à lactose. A porcentagem dos absorvedores e tolerantes $(82,2 \%)$ foi significativamente maior do que a dos absorvedores e intolerantes (40,0\%). O odds ratio igual a 6,9 indica forte associação positiva entre absorção e tolerância à lactose. Isto significa que a probabilidade dos bons absorvedores apresentarem tolerância é 6,9 vezes maior do que aquela apresentada pelos bons absorvedores e que se mostraram intolerantes à lactose (Tabela 1).

\section{$\operatorname{Com} \Delta \mathrm{H}_{2}>10 \mathrm{ppm}$}

Quando se diminui o ponto de corte do $\mathrm{DH}$, ocorre um aumento do número de maus absorvedores: 37 (44,5\%) indivíduos, sendo que 8 deles também apresentaram sinais de intolerância.

$\mathrm{O}$ teste exato de Fisher mostrou associação estatisticamente significante $(\mathrm{P}<0,05)$ entre absorção e tolerância à lactose. A porcentagem dos absorvedores e tolerantes $(60,3 \%)$ foi significativamente maior do que a dos absorvedores e intolerantes à lactose
$(20,0 \%)$; o odds ratio calculado para esta variável foi 6,1 .

\section{Absorção e tolerância à lactose e a pre- sença ou não de parasitas nas fezes $\operatorname{Com} \Delta \mathrm{H}_{2}>20 \mathrm{ppm}$}

O teste exato de Fisher demonstrou associação estatisticamente significante $(\mathrm{P}<0,05)$ entre os bons absorvedores $\mathrm{e}$ tolerantes à lactose e a presença ou ausência de parasitas nas fezes.

A porcentagem de bons absorvedores e tolerantes à lactose, com ausência de parasitas nas fezes $(81,1 \%)$ foi significativamente maior do que a dos indivíduos absorvedores e tolerantes com parasitas presentes nas fezes $(56,7 \%)$

Obteve-se odds ratio de 3,3, demonstrando associação positiva entre absorção e tolerância à lactose e a presença ou não de parasitas nas fezes. Isto significa que a probabilidade dos bons absorvedores/tolerantes e ausência de parasitas nas fezes é 3,3 vezes maior do que

Tabela 1 - Má absorção de lactose: associação com o local de moradia, intolerância à lactose, estado nutricional e a presença ou não deparasita nas fezes dos escolares

\begin{tabular}{|c|c|c|c|c|}
\hline & \multicolumn{2}{|c|}{$\begin{array}{l}\text { Má absorção de lactose } \\
\qquad \mathrm{H} 2>20 \mathrm{ppm}\end{array}$} & \multirow[b]{2}{*}{ Total } & \multirow[b]{2}{*}{ Má absorção \% } \\
\hline & Presente $(n=19)$ & Ausente $(n=64)$ & & \\
\hline \multicolumn{5}{|l|}{ Local de moradia } \\
\hline Zona urbana ou rural & 15 & 48 & 63 & 23,8 \\
\hline Favela & 4 & 16 & 20 & 20,0 \\
\hline \multicolumn{5}{|l|}{ Intolerância à lactose } \\
\hline Sim & 6 & 4 & 10 & 60,0 \\
\hline Não & 13 & 60 & 73 & 17,8 \\
\hline \multicolumn{5}{|l|}{ Desnutrição } \\
\hline Sim & 1 & 7 & 8 & 12,5 \\
\hline Não & 18 & 57 & 75 & 24,0 \\
\hline \multicolumn{5}{|l|}{ Parasitose intestinal } \\
\hline Sim & 10 & 20 & 30 & 33,3 \\
\hline Não & 9 & 44 & 53 & 16,9 \\
\hline
\end{tabular}


aquela apresentada pelos bons absorvedores e tolerantes à lactose e com presença de parasitas nas fezes (Tabela 1).

\section{$\mathrm{Com} \mathrm{DH}_{2}>10 \mathrm{ppm}$}

O teste exato de Fisher mostrou associação estatisticamente significante $(\mathrm{P}<0,05)$ entre os absorvedores e tolerantes à lactose $\mathrm{e}$ a presença ou não de parasitas nas fezes. A porcentagem dos bons absorvedores/tolerantes e ausência de parasitas nas fezes $(62,3 \%)$ foi expressivamente maior do que dos bons absorvedores e tolerantes à lactose com presença de parasitas nas fezes $(36,7 \%)$. $\mathrm{O}$ odds ratio calculado foi 3,3.

\section{Absorção e tolerância à lactose e o estado nutricional}

O teste exato de Fisher não mostrou associação estatisticamente significante entre os absorvedores e tolerantes à lactose e seu estado nutricional, quando utilizou-se o $\mathrm{DH}_{2}>20 \mathrm{pmm}$, assim como, quando o ponto de corte foi $\mathrm{DH}_{2}>10 \mathrm{ppm}$ (Tabela 1).

\section{Absorção e tolerância à lactose e a ocor- rência de sobrecrescimento bacteriano $\operatorname{Com} \Delta \mathrm{H}_{2}>20$ ppm}

O teste exato de Fisher não mostrou associação estatisticamente significante $(\mathrm{P}=0,2077)$ entre os absorvedores/tolerantes à lactose e aqueles com teste anormal após sobrecarga com lactulose, ou seja, não se detectou associação entre essas variáveis no presente trabalho.

\section{$\operatorname{Com} \Delta \mathrm{H}_{2}>10 \mathrm{ppm}$}

Mesmo diminuindo o ponto de corte, não houve associação estatisticamente significante
$(\mathrm{P}>0,05)$ entre os absorvedores e tolerantes à lactose e o teste de $\mathrm{H}_{2}$ com lactulose, demonstrando sobrecrescimento bacteriano.

\section{Sobrecrescimento bacteriano e a pre- sença ou não de parasitas nas fezes}

Não se detectou associação entre o teste do $\mathrm{H}_{2}$ utilizando lactulose e a presença ou não de parasitas nas fezes desses escolares, segundo o teste exato de Fisher $(\mathrm{P}>0,05)$ (Tabela 2).

\section{Sobrecrescimento bacteriano e o estado nutricional}

Utilizando-se o teste exato de Fisher $(\mathrm{P}>0,05)$, não se observou associação entre o estado nutricional e o teste do $\mathrm{H}_{2}$ com lactulose (Tabela 2).

Tabela 2 - Sobrecrescimento bacteriano no intestino delgado de escolares de acordo com o teste do hidrogênio no ar expirado após administração de 10 gramas de lactulose

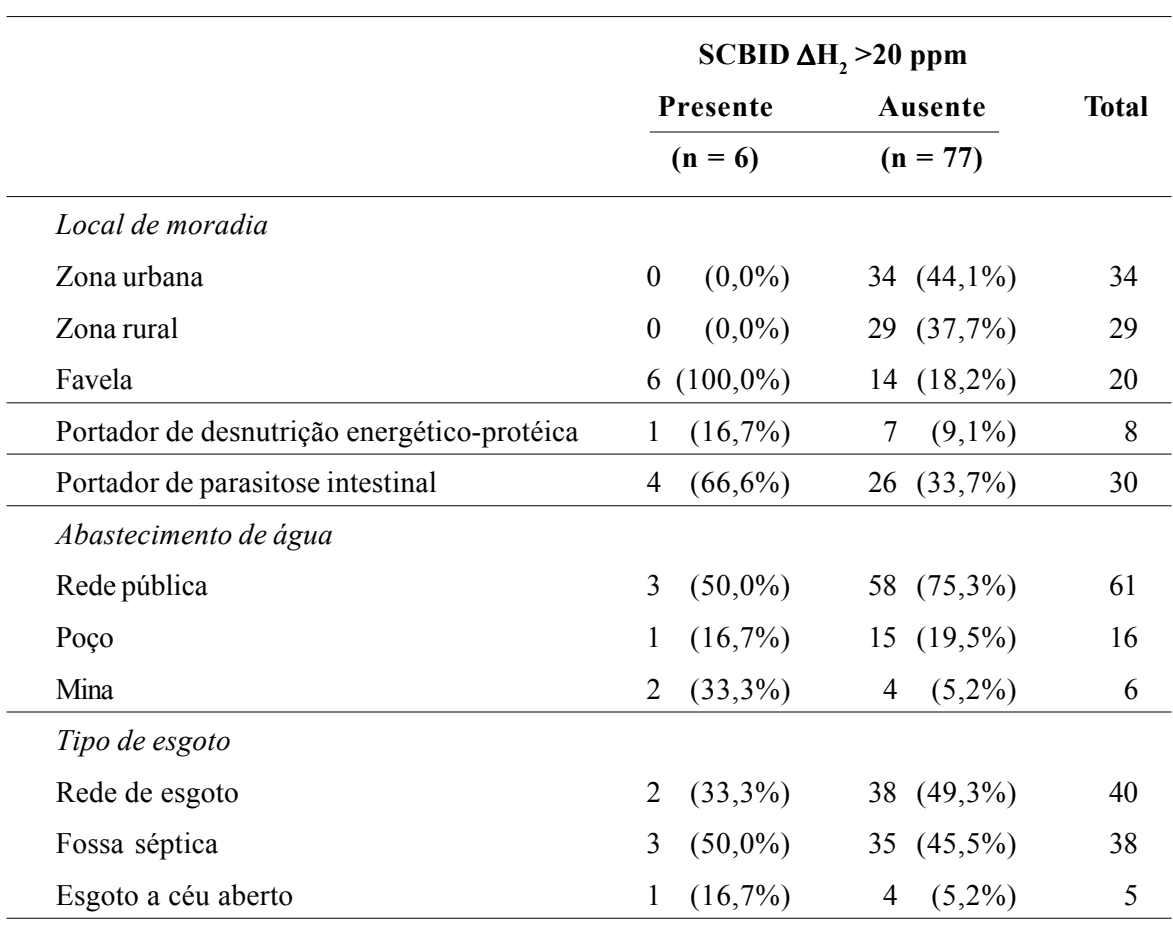


assim, alimentar-se com lactose não impedirá declínio da sua atividade, caso isto tenha sido determinado geneticamente ${ }^{(17,21,22)}$.

A deficiência ontogenética de lactase é extremamente variável entre as diferentes raças e populações ${ }^{(21,23)}$. Em brancos europeus, a prevalência de hipolactasia é baixa, chegando a 5\% ou menos nas populações escandinavas. $\mathrm{Na}$ África é extremamente variável, sendo menor que $40 \%$ em nômades e maior que $70 \%$ em outras populações ${ }^{(21)}$. Na Ásia tende a ser muito alta, atingindo 60 a 100\% dos indivíduos $^{(13)}$. Na América Latina, a população de maus absorvedores oscila entre 45 e $94 \%{ }^{(23)}$.

Em brasileiros, alguns estudos mostram incidência de 46 a $67 \%$, com grandes variações quando se considera a etnia ${ }^{(8,24,28)}$. Neste estudo, a ocorrência de deficiência ontogenética de lactose $(22,9 \%)$ foi inferior a que se acreditava existir em nosso meio, provavelmente, pela dose mais próxima da fisiológica, utilizada no teste de absorção.

Má absorção de lactose pode ser investigada por diversas metodologias, embora nenhuma delas estabeleça um padrão-ouro ${ }^{(4)}$. Portanto, o teste a ser escolhido dependerá das facilidades técnicas de cada serviço, bem como das finalidades a que se propõe. A investigação da má absorção de lactose tornouse mais simples com a utilização do teste respiratório de $\mathrm{H}_{2}$ no ar expirado. Apesar de ser um método indireto, correlaciona-se bem com os níveis intestinais de lactase e apresenta boa sensibilidade e especificidade $^{(17,27)}$.

Quando se utiliza o teste do $\mathrm{H}_{2}$ no ar expirado, há vários trabalhos na literatura pediátrica que concordam com o critério de PERMAN et al. ${ }^{(18)}$ ao estabelecer o ponto de corte em DH $>10$ ppm. CASKEY et al. ${ }^{(7)}$ encontraram $\mathrm{DH}_{2}>17 \mathrm{ppm}$ para separar indivíduos bons absorvedores e maus absorvedores de lactose em nativos americanos. Outros autores tais como BROWN et al. ${ }^{(3)} \mathrm{em}$ Bangladesh, SOLOMONS e BARILLAS ${ }^{(26)}$ e VELIGATI et al. ${ }^{(30)}$, acreditam que o $\mathrm{DH}_{2}>20$ ppm seja o melhor critério de corte para separar bons absorvedores e maus absorvedores, na população pediátrica. Nossos resultados se mostraram mais concordantes com o critério de corte em $\mathrm{DH}_{2}>20$ ppm, pois este valor apresentou maior correlação com a presença ou não de sintomas clínicos de intolerância à lactose.

Por outro lado, a enteropatia ambiental sintomática e/ou assintomática constituem grave problema de saúde pública em grupos populacionais de baixo nível sócio-econômico de nosso meio ${ }^{(11)}$. A ocorrência de SCBID com enteropatia ambiental, foi caracterizada em crianças moradoras em favelas ${ }^{(9,10)}$. SCBID é caracterizado pela presença de bactérias pertencentes à flora colônica no intestino delgado e pode levar à diarréia e à desnutrição, devido à má absorção de proteínas, gorduras, carboidratos, vitaminas e perda de água e eletrólitos $^{(19,29)}$. A cultura e a contagem de colônias do aspirado do intestino delgado alto é considerado padrão-ouro para o diagnóstico de SCBID $^{(14)}$, por ser método direto e específico, porém há uma série de dificuldades para o emprego desta técnica de forma rotineira. $\mathrm{O}$ teste do hidrogênio no ar expirado, pode ser uma alternativa não invasiva e que mantém a sensibilidade e especificidade semelhante à cultura do aspirado duodenal ${ }^{(14)}$.

FAGUNDES-NETO et al. ${ }^{(10)}$ estudando crianças faveladas sem diarréia na cidade de São Paulo, observaram um alto índice de identificação de enteropatógenos nas fezes.
Os resultados chamaram a atenção para o elevado número de portadores assintomáticos, refletindo um alto índice de contaminação ambiental em população desprovida de recursos higiênicos. Neste presente estudo, com crianças assintomáticas, o teste do $\mathrm{H}_{2}$ no ar expirado revelou-se positivo para SCBID em seis $(7,2 \%)$ escolares, todos habitantes da favela. Presença de algum parasita nas fezes foi observada em $30(36,1 \%)$ destes escolares, sendo que em 16 dos 20 alunos habitantes da favela. Sobrecrescimento bacteriano encontrado neste grupo de crianças assintomáticas, pode refletir as condições desfavoráveis de seu meio ambiente.

\section{CONCLUSÕES}

1. A deficiência ontogenética de lactase neste grupo de indivíduos foi semelhante ao encontrado nas populações caucasianas.

2. O critério de corte, $\mathrm{DH}>20 \mathrm{ppm}$, para classificar o indivíduo como mau absorvedor de lactose, apresentou melhor correlação com a ocorrência de intolerância a este carboidrato.

3. Giardia lamblia foi o parasita mais freqüentemente isolado.

4. Nos escolares que apresentaram exame parasitológico de fezes positivo, houve maior probabilidade de também ocorrer má absorção e/ou intolerância à lactose.

5. A presença de SCBID neste grupo de crianças, provavelmente, representa a repercussão das condições adversas do meio ambiente sobre o hospedeiro. 
Reis JC dos, Morais MB de, Fagundes-Neto U. Teste do $\mathrm{H}_{2}$ no ar expirado na avaliação de absorção de lactose e sobrecrescimento bacteriano no intestino delgado de escolares

Reis JC dos, Morais MB de, Fagundes-Neto U. Breath hydrogen test to evaluate lactose absorption and small bowel bacterial overgrowth in children. Arq Gastroenterol, São Paulo, 36(4):169-176, 1999.

ABSTRACT - The aim of this study was to determine the lactose absorption capacity and possible existence of bacterial overgrowth in the small bowel in asymptomatic school children of low social economic level in Marilia, a city located in the interior of São Paulo state. Eighty three children aging 7 to 15 years old without any gastrointestinal manifestations at least 30 days prior to the tests were studied. All the patients had fasted for at least 8 hours before the tests were performed. Lactose absorption was evaluated by breath hidrogen test after an overload of lactose $18 \mathrm{~g}$ in $10 \%$ aquous solution. Lactose intolerance was determined by the occurrence of clinical symptoms, such as diarrhea, abdominal pain, flatulence, etc in the following 24 hours after the test was performed. Bacterial overgrowth was evaluated by the breath hidrogen test after a $10 \mathrm{~g}$ lactulose load in aqueous solution. Lactose malabsorption was detected in 19 $(22.9 \%)$ children and lactose intolerance was observed in 10 (12\%) children. Lactose intolerance was more frequently observed in children who showed lactose malabsorption (6/19; 31.6\%) than in those who presented a normal test (4/64; 6.3\%) $(P=0.008)$. Bacterial overgrowth was detected in six (7.2\%) children and showed no statistical relationship with lactose malabsorption. Ontogenetic lactose malabsorption verified in this group of school children is similar to the reported for Caucasian populations. Presence of bacterial overgrowth confirms the existence of asymptomatic environmental enteropathy in children of low social economic level.

HEADINGS - Breath tests. Lactose tolerance test. Bacteria, growth \& development. Intestine, small. Lactose. Lactulose. Students.

\section{REFERÊNCIAS BIBLIOGRÁFICAS}

1. Barr RG, Watkins JB, Perman JA. Mucosal function and breath hydrogen excretion: comparatives studies in the clinical evaluation of children with nonspecific abdominal complaints. Pediatrics, 68:526, 1981.

2. Bond J, Levitt M. Use of breath hydrogen in the study of carbohydrate absorption. Am J Dig Dis, 22:379, 1977.

3. Brown KH, Khatum PL, Ahmed MG. Lactose malabsorption in Bangladesh village children: a reappraisal. Am J Clin Nutr, 32:1962, 1979.

4. Brummer RJM, Karibe M, Stockbruegger RW. Lactose malabsorption: optimalization of investigational methods. Scand J Gastroenterol, 28(suppl.100):65, 1993.

5. Buller HA, Rings EHHM, Montgomery RK, Grand RJ. Clinical aspects of lactose tolerance in children and adults. Scand J Gastroenterol, 26(suppl. 188):73, 1991.

6. Calloway D, Murphy E. Use of expired air to measure intestinal gas formation. Ann NY Acad Sci, 150:82, 1968.

7. Caskey DA, Payne-Bose D, Welsh JD, Gearhart HL, Nance MK, Morrison RD. Effects of age on lactose malabsorption in Oklahoma native Americans as determined by breath $\mathrm{H}_{2}$ analysis. Am J Dig Dis, 22:113, 1977.

8. Duarte E, Oliveira JED. Intolerância à lactose em adultos. Rev Bras Pesq Med Biol, 11:105, 1978 .
9. $\quad$ Fagundes-Neto U, Wehba J, Viaro T, Machado NL, Patrício FRS. Protracted diarrhea in infancy: clinical aspects and ultrastructural analysis of the small intestine. J Pediatr Gastroenterol Nutr, 4:714, 1985.

10. Fagundes-Neto U. Enteropatia ambiental. Uma conseqüência do fracasso das políticas sociais e de saúde pública. Rio de Janeiro, Revinter, 1996. 199p.

11. Falcão JB. Absorção de lactose e tolerância à prova de sobrecarga: comparação entre indivíduos normais e portadores de colite ulcerativa inespecífica. São Paulo, 1997. [Dissertação de Mestrado - Escola Paulista de Medicina].

12. Faust EC, Russel PF, Jung RC. Clinical Parasitology. 8.ed. Philadelphia, Lea \& Febiger, 1970.

13. Flatz G. Genetics of lactose digestion in humans. Adv Hum Genet, 16:1, 1987.

14. King CE, Toskes PP. Small intestine bacterial overgrowth. Gastroenterology, 76:1035, 1979.

15. Kruse TA, Bolund L, Grzeschik L-H, Ropers HH, Sjostrom H, Norém O, Mantei N, Semenza G. The human lactase-phorizin hidrolase gene is located on chromosome 2. FEBS Lett, 240:123, 1988.

16. Marcelino RT, Fagundes-Neto U. Teste do hidrogênio no ar expirado no diagnóstico do supercrescimento bacteriano do intestino delgado. Arq Gastroenterol, 32:191, 1995.

17. Newcomer AD, McGill DB, Thomas PJ, Hofmann AF. Prospective comparison of indirect methods for detecting lactase deficiency. N Engl J Med, 193:1232, 1975. 
18. Perman JA, Modler S, Barr RG, Rosental P. Fasting breath hydrogen concentration: normal value and clinical application. Gastroenterology, 87:1358, 1984.

19. Pignata C, Budillon G, Monaco G, Nani E, Cuomo R, Parrili G, Ciccmarra F. Jejunal bacterial overgrowth and intestinal permeability in children with immunodeficiency syndromes. Gut, 31:879, 1990.

20. Rhodes JM, Middleton P, Jewell DP. The lactulose hydrogen breath test as a diagnostic test for small bowel bacterial overgrowth. Scand J Gastroenterol, 14:333, 1979.

21. Sahi T, Launiala K. More evidence for the recessive inheritance of selective adult type lactose malabsorption. Gastroenterology, 73:73, 1977.

22. Sahi T. Hypolactasia and lactose persistence. Historical review and the terminology. Scand J Gastroenterol, 29(suppl. 30):1, 1994.

23. Scrimshaw NS, Murray EB. Problens in the interpretation of research results. Am J Clin Nutr (suppl. 48):1137, 1988.

24. Sevá-Pereira A, Magalhães AFN, Filho RAP. Teste de sobrecarga com lactose no diagnóstico de mal-absorção primária de lactose do adulto. Rev Bras Patol Clin, 18:1, 1982.

25. Siegel S. Estatística não paramétrica (para as ciências do comportamento). São Paulo, Mc GrawHill, 1981. 350p
26. Solomons NW, Barillas C. The cut-off criterion for a positive hydrogen breath test in children: a reappraisal. J Pediatr Gastroenterol Nutr, 5:920, 1986.

27. Strocchi A, Corazza G, Ellis CJ, Gasbarrini G, Levitt MD. Detection of malabsorption of low doses of carbohydrate: accuracy of various breath $\mathrm{H}_{2}$ criteria. Gastroenterology, 105:1404, 1993.

28. Troncon LE, Collares EF, Oliveira RB, Padovan W, Meneghelli UG. Malabsorção de lactose em pacientes adultos do Hospital de Clínicas de Ribeirão Preto. Arq Gastroenterol, 18:106, 1981.

29. Vanderhoof JA, Young RJ, Murray N, Kaufman SS. Treatment strategies for small bowel bacterial overgrowth in short bowel syndrome. J Pediatr Gastroenterol Nutr, 27:155, 1998.

30. Veligati L, Treem W, Sullivan B, Burke G, Hyaams J. D10 ppm versus D20 ppm: a reappraisal of diagnostic criteria for breath hydrogen testing in children. Am J Gastroenterol, 89:758, 1994.

31. Viaro T. Observações médico-sociais em comunidade de favelados: aspecto clínico e nutricionais evolutivos em crianças no primeiro ano de vida. São Paulo, 1985 [Dissertação de Mestrado - Escola Paulista de Medicina].

32. Waterlow JC. Classification and definition of protein-energy malnutrition. Nutrition in preventive medicine. Geneve, WHO, 1976. (Monograph series $n^{\circ} 62$ ). 